\title{
Dependencia y pasividad en la selección de fuentes informativas en el periodismo radiofónico en España
}

\author{
Manuel Fernández-Sande*, Luãn Chagas**, Marcelo Kischinhevsky*** \\ *Universidad Complutense de Madrid \\ Correo-e: manuel.fernandez@ucm.es | ORCID iD: https://orcid.org/0000-0002-0740-2630 \\ **Universidade Federal de Mato Grosso (Brasil) \\ Correo-e: Iuaanchagas@gmail.com | ORCID iD: https://orcid.org/0000-0002-2491-8479 \\ ***Universidade Federal do Rio de Janeiro (Brasil) \\ Correo-e: marcelokisch@gmail.com | ORCID iD: https://orcid.org/0000-0002-4838-2162
}

Recibido: 15-09-2019; 2a versión: 13-10-2019; Aceptado: 15-10-2019.

Cómo citar este artículo/Citation: Fernández-Sande, M.; Chagas, L.; Kischinhevsky, M. (2020). Dependencia y pasividad en la selección de fuentes informativas en el periodismo radiofónico en España. Revista Española de Documentación Científica, 43 (3), e270. https://doi.org/10.3989/redc.2020.3.1712

Resumen: El artículo es el resultado de un estudio exploratorio que analiza los procesos de selección de las fuentes informativas en la producción de noticias por parte de los periodistas radiofónicos. El corpus de análisis está integrado por las noticias difundidas en los programas informativos de mediodía de las cuatro grandes cadenas españolas de ámbito estatal (Cadena SER, Cadena COPE, Onda Cero y Radio Nacional de España) durante cuatro semanas de programación. A partir de una propuesta propia de taxonomía de las fuentes periodísticas, se ha aplicado el análisis de contenido con el objetivo de conocer cómo son utilizadas estas fuentes en la construcción de las noticias y establecer posibles diferencias entre las principales secciones temáticas. Los resultados muestran una elevada dependencia respecto a las fuentes oficiales y una importante pasividad en el proceso de selección de fuentes, lo que contrasta con valores característicos presentes en el discurso teórico de la práctica profesional.

Palabras clave: Fuentes informativas; periodismo; profesión periodística; credibilidad periodística; periodismo radiofónico.

\section{Dependence and passivity in the selection of information sources in radio journalism in Spain}

Abstract: This article is the result of exploratory studies that analyses the selection processes of information sources in the news production by radio journalists. The corpus of analysis included news broadcasted on midday radio programs by the four major Spanish national networks (Cadena SER, COPE, Onda Cero and Radio Nacional de España) during a period of four weeks. Based on original taxonomy for journalistic sources, it was carried out a content analysis in order to know how these sources are used in news producing and to establish possible differences in the main thematic sections. Among the main results of the study are a higher dependence from official sources and a great degree of passivity in the process of source selection, which contrasts with the characteristic values present in the discourse of journalistic professional practice.

Keywords: Sources of information; journalism; journalistic profession; journalistic credibility; radio journalism.

Copyright: (c) 2020 CSIC. Este es un artículo de acceso abierto distribuido bajo los términos de la licencia de uso y distribución Creative Commons Reconocimiento 4.0 Internacional (CC BY 4.0). 


\section{INTRODUCCIÓN}

El periodismo radiofónico afronta en la actualidad una profunda reconfiguración tras la estela de la emergencia de las plataformas digitales. Esta evolución de la radio ha suscitado en los últimos años nuevas propuestas conceptuales que tratan de redefinir y comprender su nueva realidad, algunas de las más destacadas son la de radio expandida (Kischinhevsky, 2017), postradio (Ortiz-Sobrino, 2012) o periodismo radiofónico hipermediático (Lopez, 2010). En el actual ecosistema mediático la radiofonía está cada vez más imbricada con nuevos dispositivos y plataformas, articulándose con otros agentes del mercado de la comunicación y, dentro de ese proceso, rediseñando los hábitos de escucha y las prácticas de interacción con sus audiencias.

Todos estos cambios guardan estrecha relación con el surgimiento de las plataformas digitales (Helmond, 2015; Srnicek, 2017; Bratton, 2015) que, a partir de los años noventa, integraron la difusión de informaciones y las transacciones comerciales y financieras, lo que propició la paulatina entrada en escena de nuevos actores ajenos a la industria periodística imperante hacía décadas.

El tradicional modelo de negocio financiado por la publicidad de masas es amenazado con la migración de los anunciantes hacia las plataformas digitales de entretenimiento y comercio electrónico, que ofrecen ventajas importantes respecto a la optimización y retorno de la inversión publicitaria. El sector radiofónico, que históricamente había mostrado una gran reticencia a introducir cambios transgresores en la gestión de sus contenidos (Rodríguez-Pallares, 2016), se ha visto obligado en los últimos años a acelerar su adaptación al nuevo escenario competitivo.

La transformación de los medios de comunicación también incide en el periodismo, inmerso en plena fase de transición rumbo a una lógica postindustrial (Anderson y otros, 2013) o postfordista, caracterizada por la precarización de las relaciones laborales, rotación creciente de la mano de obra, búsquedas de sinergias a través de operaciones empresariales de fusiones y adquisiciones, integración de redacciones de diferentes medios (periódicos, radios, televisiones, sitios web informativos), y dependencia financiera de grandes anunciantes. Los cambios son tan profundos que obligan a los investigadores a indagar en lo que se está convirtiendo este nuevo periodismo, hasta el extremo de relegar el debate teórico sobre lo que es el periodismo (Deuze y Witschge, 2016).
En este contexto, ganan importancia no solo las investigaciones vinculadas a la perspectiva de la sociología del trabajo aplicada al campo periodístico para analizar culturas organizacionales, condiciones laborales o discursos corporativos (el del periodista emprendedor, por ejemplo); sino que también resurge la relevancia de los análisis de contenido que permitan verificar las informaciones y contenidos que los medios están difundiendo, así como comprender los encuadres y tratamientos informativos que se están aplicando en un entorno cada vez más competitivo.

La selección de las fuentes de información se convierte, por tanto, en una cuestión central en el proceso de dar voz o silenciar a los agentes sociales que se disputan la atención informativa. La búsqueda por el espacio mediático, en un mercado cada vez más fragmentado, pero en el que todavía se mantienen notables liderazgos de audiencia, se erige en una estrategia que incluye a grupos políticos, empresariales, organizaciones sociales, ciudadanos comunes y a la propia comunidad interpretativa del periodismo.

El presente artículo pretende profundizar en el tema de la selección de fuentes informativas en el periodismo radiofónico, entendido como un asunto central para la investigación de la diversidad y el pluralismo de las voces a las que los oyentes tienen acceso, puesto que condiciona la interpretación de las noticias y la consiguiente formación de juicios de valor sobre la agenda pública, medida en este caso a través de la comunicación radiofónica.

La primera fase del estudio consistió en el desarrollo de una taxonomía propia de las fuentes periodísticas, con el fin de clasificar de forma precisa cada una de las fuentes mencionadas en las noticias integrantes del corpus de análisis.

El análisis de contenido sonoro se realizó mediante la grabación de los programas informativos seleccionados durante las semanas del 3 al 7 de septiembre de 2018 (Cadena SER y COPE), y del 10 al 14 del mismo mes (Onda Cero y Radio Nacional de España). En el desarrollo teórico-metodológico de la investigación se buscó verificar cómo la selección de las fuentes es un proceso influenciado por aspectos directamente involucrados con los valores de la comunidad interpretativa de los periodistas (Zelizer, 2004; Traquina, 2005), así como por relaciones de dependencia (Franklin, 2011; Manning, 2001) y pasividad (Elías, 2003; Van Hout, 2011; Reich, 2011) en el momento de la selección y construcción de las diversas fuentes que constituyen el sustrato de las informaciones. 


\section{MARCO TEÓRICO}

\subsection{La comunidad interpretativa y los valores compartidos}

Se parte de la discusión teórica en torno a la comunidad interpretativa del periodismo, de los valores compartidos y de las diversas formas en que los cambios resultantes de la innovación tecnológica y de las diferentes crisis económicas han afectado al conjunto de las redacciones. Para ello, se han revisado los resultados de investigaciones empíricas previas desarrolladas, sobre todo, en el ámbito iberoamericano (Moreira, 2016; Berganza y otros, 2018; Amado y Waisbord, 2018; Traquina, 2005; Zelizer, 2004; Leal y Jácome, 2013).

La selección de las fuentes es una cuestión discutida desde las primeras investigaciones funcionalistas que buscaban entender los parámetros de influencia en las decisiones de los seleccionadores de noticias (gatekeepers) (White, 1999) o en la organización periodística (Breed, 1999). Como destaca Zelizer (2014), sustentar el fenómeno del grupo social en el caso de los periodistas es fundamental para conocer sus estrategias y la forma en que interpretan el mundo.

En el caso de los estudios de periodismo, el desarrollo de comunidades interpretativas se origina por diferentes caminos y visiones a lo largo del tiempo, ya sea a través de las reflexiones de los propios periodistas o de profesores e investigadores del área. El marco teórico de la comunidad interpretativa procede de los conocimientos de disciplinas tan diversas como la historia, la antropología, la sociología y la psicología social. Con el desarrollo del estudio sistemático de la práctica periodística se prescindió paulatinamente de la concepción del periodista como un profesional que seleccionaba las noticias por mera intuición u olfato; por el contrario, se le percibe como un profesional que cumple con una rutina compleja, a lo largo de su jornada laboral, sin la que no es posible comprender el proceso de producción de las noticias (Zelizer, 2004). Esa noción va más allá de la idea del periodismo entendido como mera narración de historias o comentarios contextualizados; entiende la noticia como aquella información que suscita un interés colectivo, un interés compartido por gran parte del público. Alsina (1993) utiliza esta concepción de la noticia como la base del contrato fiduciario que sustenta el profesionalismo periodístico.

Ese reconocimiento del público sobre la importancia de las noticias delega a sus productores, los periodistas, la función de seleccionar aquello que debe suscitar interés colectivo. Por más que algu- nos autores defiendan el fin de ese monopolio en la selección de las informaciones con el desarrollo de Internet y los nuevos canales digitales, las estrategias de búsqueda de información de los nuevos medios no han variado de forma sustancial, principalmente en lo que concierne a la valoración del concepto de noticia y los criterios de noticiabilidad (Traquina, 2005; Silva y otros, 2014).

Casals (2005) vincula la credibilidad del relato periodístico con la correcta identificación de las fuentes. López (1995) define las fuentes como los testimonios en los que el periodista se basa para escribir sus relatos sobre la actualidad y que constituyen "todo aquel canal -persona o institución- que proporciona datos sustanciales o complementarios -al ser testigo directo o indirecto- para poder confeccionar noticias, reportajes, crónicas e informes". Para De Fontcuberta (1993) las fuentes periodísticas son las "personas, instituciones y organismos de toda índole que facilitan la información que necesitan los medios para suministrar noticias".

Todas las creencias y características presentes en las redacciones de los medios se combinan con otros valores fundamentales que determinan los procesos de selección y construcción de las noticias: la elección de las fuentes, la búsqueda por reafirmar criterios comunes respecto al contexto, la valoración de la importancia e interés del acontecimiento, los preceptos en torno a la notoriedad de los personajes protagonistas de la noticia y la estimación del impacto que generará la noticia en los diferentes públicos de interés, entre otros.

Son valores periodísticos socialmente construidos y compartidos, aunque la forma en que se aplican pueda estar cada vez más cuestionada, y no solo por la comunidad interpretativa. Podríamos identificar muchos factores que inciden en el debilitamiento de algunos de esos preceptos. Una tendencia preocupante es que buena parte de los periodistas no tiene oportunidad de salir a la calle en busca de las noticias y pasa la mayor parte de su jornada de trabajo en la redacción, sentados frente a sus ordenadores, limitándose a seleccionar y editar contenidos o reempaquetar informaciones, en lugar de entrevistar directamente a las fuentes y buscar primicias informativas (Neveu, 2006; Pereira, 2004). El periodista que ejerce su función de esta forma tan pasiva es mucho más dependiente de sectores externos a la redacción en la producción y construcción de las noticias, sobre todo en un escenario de "revolución de las fuentes" (Chaparro, 1994), en que grupos económicos y políticos administran un flujo diario creciente de informaciones de una forma profesionalizada. 
En este contexto de los medios, una visión crítica de los actuales procesos de producción de noticias no debe interpretarse como un juicio negativo generalizado sobre el trabajo realizado por los periodistas, quienes en muchos casos mantienen situaciones de precariedad laboral. No resulta certero interpretar las posibles deficiencias detectadas en las prácticas periodísticas como un fracaso atribuible exclusivamente al incumplimiento, por parte de los periodistas, de una serie de ideales construidos en torno a su ejercicio profesional, como garantizar el contraste de fuentes, la diversidad de opiniones o la independencia ante los diferentes poderes; si es que estos atributos, en algún momento, llegaron a traspasar la esfera mítica para ser aplicados en la producción real de la información. Son también numerosos los factores externos que están interfiriendo en el actual proceso de construcción de las noticias, los estudios de utilización de las fuentes informativas permiten identificar algunos de ellos.

Casero-Ripollés y López (2012) identifican dos grandes líneas de investigación en el estudio de las fuentes: la primera de ellas pone el foco en la relación entre los periodistas y los políticos -que actúan como fuentes de información-; la segunda plantea la gestión de las fuentes como criterio de calidad en el trabajo periodístico. Se puede añadir una tercera línea, desarrollada en los últimos años, centrada en el análisis de las rutinas profesionales y otros condicionantes organizacionales, en el ámbito de las empresas periodísticas, entendidos como factores determinantes en la gestión de las fuentes informativas.

\subsection{Dependencia y pasividad en la selección de las fuentes}

Diversas investigaciones vienen señalando las transformaciones del perfil profesional del periodista, ahora requerido para realizar múltiples tareas, en una profesión debilitada. En España, MarquesHayasaki y otros (2016), constataron cambios profundos en las últimas décadas. La adaptación a los medios digitales y la aparición de medios nativos consolidaron, en el plano del discurso sobre la práctica periodística, conceptos clave que se interpretan como características profesionales deseables para el periodista en la actualidad. Entre ellos, el dominio de conocimientos sobre hipertextualidad, multimedia, interacción y capacidad de personalización de las noticias. A estos atributos se suman otros tres elementos apuntados por los investigadores: a) la búsqueda por mayor diversidad étnica tanto entre los profesionales como en los tratamientos informativos, por ejemplo, en las voces presentes en las informaciones; b) la capacidad para combinar en los relatos la información y el entretenimiento (el llamado infoentretenimiento); y c) el surgimiento de un periodismo online, en transformación permanente, que asienta en la velocidad la validez de cualquier contenido informativo, lo que paradójicamente puede llegar a comprometer la propia credibilidad de las informaciones. La evolución del perfil profesional de los periodistas se ha consolidado como uno de los temas centrales de investigación en el área (López-García, 2002; Salaverría, 2006; Salaverría y García-Avilés, 2008; Mellado y otros, 2007; Scolari y otros, 2008; Túñez y otros, 2010; Martín, 2012; Gómez-Calderón y otros, 2017; López-García y otros, 2017).

Berganza y otros (2018), identifican diferentes tendencias preocupantes sobre la evolución de la profesión periodística en los últimos años: precarización creciente de la profesión, descenso de los estándares éticos, pérdida de autonomía editorial frente a numerosas presiones, cambios en las rutinas profesionales y aceleración de los procesos de producción periodística.

El factor tiempo se ha convertido en un problema central en el proceso de construcción de las noticias y la investigación de los temas, principalmente en los medios privados, que han sufrido más el impacto de la crisis.

Las fuentes articuladas, como agentes interesados en influir sobre las noticias, se caracterizan por una gran proactividad desarrollando acciones estratégicas en el campo periodístico que se fundamentan sobre los problemas, rutinas y circunstancias del trabajo de los profesionales en las redacciones. La proactividad de estos agentes llega a influenciar ya no solo los procesos de selección de noticias de los medios, sino las propias ideas y valores compartidos por la comunidad interpretativa que conforman los periodistas, según señala Traquina (2005).

Autores como Mayoral y Romero (2009) en el caso español, Gans (1980), Schlesinger (1978), Sigal (1973) y Molotch y Lester (1999) siguen estos mismos parámetros comprobando empíricamente, en sus respectivos estudios, la hegemonía del uso de las fuentes oficiales o poderosas que se terminan imponiendo en las rutinas profesionales de las redacciones.

En su investigación sobre la prensa local en España, Pérez-Curiel y otros (2015) verifican "la proximidad geográfica, la relevancia social de las fuentes y la fractura del consenso social establecido" como los tres valor-noticias más habituales en las informaciones difundidas por los medios. Uno de ellos, central en nuestra investigación, es la proximidad/accesibilidad de la fuente -sobre todo en la cobertura cotidiana y local de los acontecimientos, como criterio fundamental para la selección de las 
fuentes. Para Pérez-Curiel y otros (2015) "La posibilidad de estar en contacto directo con las fuentes favorece que los medios elaboren más temas propios, fundamentados en contenidos de primera". Sin embargo, como señalan en su investigación, el $52,8 \%$ de las 591 noticias analizadas presentaban apenas una sola fuente de información, y el 8,6\% no hacían alusión a ninguna procedencia. Las noticias que fueron resultado directo de la cobertura en la calle de los periodistas, representaron el $38,2 \%$ del total de informaciones analizadas de la sección local, un porcentaje mucho más elevado del que alcanza este tipo de noticias en secciones como economía o cultura, en las que predominan las informaciones originadas por el llamado periodismo de convocatoria. En este trabajo se advierte sobre el "círculo cerrado" que se genera entre las fuentes oficiales y los periodistas, uno de cuyos efectos es la exclusión de sectores amplios de la sociedad, sin capacidad para erigirse en fuente, de la atención informativa de los medios.

Berganza y Chaparro (2012) analizaron las diferencias de uso de fuentes periodísticas entre la prensa gratuita y de pago en España. Entre los resultados de su minucioso estudio destaca el escaso uso de fuentes en las noticias publicadas por la prensa gratuita (el $62,5 \%$ de las noticias analizadas no indicaban ninguna fuente), pero también resulta muy llamativo el amplio número de noticias $(34,4 \%)$ publicadas en periódicos de pago que tampoco citaban ni una sola fuente.

Los resultados de estas investigaciones apuntan a una limitada pluralidad y diversidad de las fuentes utilizadas por los periodistas en su trabajo cotidiano, aunque estos sean valores y conceptos presentes en todos los cánones profesionales. En ese contexto de las rutinas profesionales, determinadas fuentes y voces se ven marginadas en el proceso de construcción y producción de las noticias. Manning (2001) ha acuñado el término de "línea de producción electrónica" de informaciones para desarrollar su visión crítica respecto a las situaciones que envuelven la dinámica cognitiva de los procesos de selección y tratamiento informativo desarrollados por los periodistas sobre la realidad social.

Es importante abordar la idea de credibilidad periodística en lo referido a las fuentes. El investigador israelí Reich (2011) destaca que la "familiaridad" y la "credibilidad" están asociadas al modelo de selección aplicado por la comunidad profesional, lo que refuerza la jerarquía de las fuentes a partir de la regularidad del contacto que se mantenga con ellas y su capacidad de generar informaciones. En este estudio comprobó que las "fuentes de información experimentadas tienen pocas ventajas respecto a organizaciones que gestionan su comu- nicación de forma profesionalizada". Reich advierte que los periodistas tan solo verifican un tercio de las noticias que proceden de fuentes con un nivel elevado de credibilidad atribuida.

Las relaciones de dependencia entre la comunidad profesional de los periodistas y las fuentes informativas inciden en los valores, los criterios de noticiabilidad y las propias noticias. Elías (2003), en su investigación sobre el uso de fuentes en el ámbito del periodismo científico, constató, a partir de la observación participante, que la selección de noticias realizada por la fuente (gabinete) jamás se hace atendiendo a los intereses de la sociedad o del periodista de los medios, se desarrolla bajo el prisma del interés de la fuente. Por ello, el esfuerzo del gabinete siempre se dirige a reforzar y destacar las noticias que favorecen a la fuente y ocultar o minimizar todas aquellas noticias que se perciban como negativas para sus intereses organizacionales.

Mayoral (2005) coincide con esta visión crítica sobre la actuación de las fuentes articuladas: "las fuentes actúan llevadas por la ambición de prefabricar un relato de los hechos". Entre las conclusiones de su estudio destaca que el $52 \%$ de la información aportada por las fuentes siempre afecta a sus intereses particulares. Lo más preocupante, si atendemos a parámetros de calidad y credibilidad periodísticas, es que, según señala Elías, el periodista de los medios "contrasta pocas veces lo que le llega de un gabinete de prensa oficial" (Elías, 2003). De Pablos (2006) advierte que cuando los medios claudican bajo esta presión de las fuentes el periodismo se transforma en propaganda.

Van Hout (2011) también ha investigado acerca de la dependencia y pasividad de los periodistas frente a las fuentes oficiales, generalmente gestionadas a través de gabinetes de prensa. El periodista suele aceptar lo que transmite la fuente por el estatus que representa, produciéndose de esta forma lo que Reich (2011) define como interacción fuente-medio unilateral y recíproca. Aunque la práctica profesional que se desarrolla en el medio incluya las características propias del trabajo periodístico como la selección, verificación y difusión de la noticia, Van Hout (2011) concluye que la pasividad se manifiesta en una falta de cuestionamiento respecto a lo que transmite la fuente, lo que condiciona la construcción de la noticia final.

García-Santamaría (2010), a partir de un pormenorizado análisis de caso del uso de las fuentes por parte de la prensa española ante el accidente aéreo de la compañía Spanair (Madrid, 20-8-2008), señala la falta de una metodología precisa en el periodismo de fuentes por parte de los profesionales, la ausencia de otras fuentes primarias, y las carencias en el 
manejo de las fuentes especializadas, como las principales causas de las deficiencias en el tratamiento informativo y del "alineamiento acrítico" de la noticia con el relato construido por las fuentes oficiales.

O'Neill y O'Connor (2008) y Franklin (2011), confirman la hipótesis de la pasividad del trabajo periodístico respecto a determinadas fuentes. En sus respectivos estudios coinciden en señalar la dependencia y pasividad respecto a las fuentes como situaciones contextuales determinantes en el trabajo periodístico, de las que se benefician las estructuras de poder para el control del flujo de las noticias.

Al contrario de lo que debería realizar un periodista activo en búsqueda de la información, que cruza datos, contrasta fuentes y busca diversificar las distintas versiones de un mismo acontecimiento, el periodista pasivo se limita a seleccionar aquellas noticias a las que tiene un acceso más sencillo, generalmente procedentes de fuentes oficiales a las que se les otorga una mayor credibilidad por el estatus que representan. Este desequilibrio en el acceso y uso de las fuentes representa una amenaza para el desarrollo de las funciones periodísticas básicas y, en última instancia, para el correcto funcionamiento democrático de la sociedad.

Esta concepción crítica y problemática sobre el periodismo actual por el predominio de las fuentes oficiales también es compartida por Franklin (2011), quien llega a formular la idea de un quinto poder, formado por el sector de las relaciones públicas, que se sobrepone al cuarto poder que, tradicionalmente, se ha asociado a los medios de comunicación. Para este autor "la influencia de las relaciones públicas fue extensa, duradera y expansiva" a lo largo de las últimas tres décadas. La dependencia periodística de los datos e informaciones proporcionados por los gabinetes de comunicación, acentuada por la crisis económica que afrontan las empresas periodísticas, forma parte de una estrategia programática ideológica entre aquellos que dominan los medios de comunicación y, al mismo tiempo, el poder económico-político de nuestras sociedades (Franklin, 2011).

En muchos casos, esta pasividad en la cobertura periodística se llega a materializar en la transcripción directa de textos producidos por departamentos de comunicación de empresas o instituciones. Esta práctica profesional, que contraviene los valores clásicos del periodismo, puede encontrarse en cualquiera de las secciones informativas presentes en los medios (política nacional, internacional, sociedad, economía, cultura, etc.)

Casero-Ripollés y López (2012) en su ambicioso estudio longitudinal sobre la gestión de las fuentes informativas por parte de la prensa española, entre los años 1980-2010, a partir del análisis de las informaciones aparecidas en portada de los diarios El País y $A B C$, constataron una tendencia que contraviene con esta perspectiva negativa del uso de fuentes en el periodismo actual. En el periodo analizado observaron un incremento significativo en el número de las fuentes utilizadas, y también una mayor diversidad, con la presencia creciente de fuentes alternativas, si bien, las fuentes institucionales -principalmente vinculadas al poder político- mantuvieron una "sobrerrepresentación" en las noticias.

No se localizan investigaciones centradas en el uso de las fuentes informativas en el periodismo radiofónico. En la radio, por las especificidades de su lenguaje, la identificación de las fuentes se convierte, en muchos casos, en una tarea más compleja que en el estudio de otros medios, pues las notas y comunicados de prensa se suelen reprocesar con otros materiales periodísticos, en ocasiones procedentes de agencias de noticias $u$ otros proveedores de información. Incluso, en ocasiones, el comunicado de prensa facilitado por la fuente -en su totalidad o alguno de sus fragmentos- es leído como información propia de la emisora.

Para el análisis de las fuentes periodísticas en radio resulta necesario prestar especial atención a la presencia de declaraciones directas de los protagonistas de las noticias, a través de lo que en el medio se conoce como "cortes de voz". La voz de los propios protagonistas de la noticia conlleva una corporeidad de la fuente referenciada y refuerza la percepción de realidad y veracidad para gran parte de la audiencia. Si alguien está hablando sobre un determinado acontecimiento, el oyente tiende a considerar que el mencionado hecho ha acontecido realmente. Las voces difundidas desempeñan un papel central en la narrativa radiofónica de los acontecimientos cotidianos, más allá de las controversias que ocasionalmente rodean las noticias y cuestionan el papel del medio en la construcción social de la realidad.

\section{METODOLOGÍA}

\subsection{Objetivos de la investigación}

En un contexto de crisis de credibilidad de los medios de comunicación y de importantes transformaciones en los procesos de producción, difusión y comercialización de la radio, el objetivo general de este trabajo es conocer cómo los periodistas radiofónicos españoles están utilizando las fuentes informativas.

El estudio exploratorio partió de los siguientes objetivos específicos de investigación: 
O1. Verificar si están siendo aplicados criterios profesionales esenciales en la gestión periodística de las fuentes informativas, como el contraste y la diversidad, a partir de conocer el número de fuentes utilizadas en las noticias.

O2. Identificar posibles diferencias en la tipología, características y preferencias en el uso de determinadas fuentes entre las distintas secciones y temáticas presentes en los espacios informativos radiofónicos.

O3. Comprobar si estos programas informativos están utilizando aplicaciones de mensajería instantánea o redes sociales para facilitar la incorporación del ciudadano como fuente informativa.

La investigación pretende verificar si la selección y utilización de fuentes en los programas informativos radiofónicos son influenciadas por aspectos presentes en los valores de la comunidad interpretativa formada por los periodistas (Zelizer, 2004; Traquina, 2005). En particular, si las relaciones de dependencia (Franklin, 2011; Manning, 2001), y pasividad (Elías, 2003; Van Hout, 2011; Reich, 2011), pueden resultar factores condicionantes en el proceso de gestión de las fuentes periodísticas.

El estudio partió de las siguientes hipótesis:

H1. Se utiliza un número reducido de fuentes periodísticas en las noticias como resultado de la dependencia de las fuentes oficiales en las temáticas analizadas.

H2. Las fuentes oficiales presentan una gran hegemonía originada por la mayor credibilidad que le atribuyen los periodistas.

H3. Los ciudadanos como fuentes informativas tienen una mayor presencia en las secciones de sociedad que en secciones como política o economía.

\subsection{Estrategias metodológicas}

Para el desarrollo de la investigación se optó por un diseño metodológico basado en la técnica del análisis de contenido: "técnica de investigación para la descripción objetiva, sistemática y cuantitativa del contenido manifiesto de las comunicaciones que tiene como objetivo interpretarlas." (Berelson, 1984). El análisis de contenido está sobre todo orientado para la realización de investigaciones empíricas y exploratorias. Bardin define este método como el "conjunto de técnicas de análisis de las comunicaciones tendentes a obtener indicadores (cuantitativos o no) por procedimientos sistemáticos y objetivos de descripción del contenido de los mensajes permitiendo la inferencia de conocimientos relativos a las condiciones de producción/recepción (contexto social) de estos mensajes" (Bardin, 2002). El análisis de contenido permite formular, a partir de los datos seleccionados, inferencias válidas aplicables en un contexto determinado (Krippendorff, 1990).

Si bien en la literatura científica es posible localizar investigaciones sobre fuentes periodísticas en las que se han aplicado otras técnicas de investigación, como la observación participante o las entrevistas en profundidad, el análisis de contenido es hasta el momento la herramienta metodológica más utilizada (Mayoral, 2005; Berganza y Chaparro, 2012; Casero-Ripollés y López, 2012).

Una de las principales características de esta técnica es su gran adaptabilidad al campo de conocimiento y los objetivos perseguidos. Para esta investigación se ha diseñado un código de análisis de contenido que permite obtener el máximo de información posible sobre las fuentes periodísticas utilizadas en las informaciones difundidas por las emisoras.

Para la investigación se seleccionaron las cuatro principales cadenas generalistas de ámbito estatal de la radio española (Cadena SER, Cadena COPE, Onda Cero y Radio Nacional de España, Radio 1). Tres de titularidad privada y una -Radio Nacional de España- de titularidad pública estatal. En el ámbito de la radio generalista en España, las cuatro cadenas aglutinaron el $87,65 \%$ del total de la audiencia del año 2018 según los datos del EGM (AIMC, 2019). A pesar de que en el dial de la radio española existen formatos de radio de temática informativa, se consideró que, para realizar un estudio comparado, resultaba más significativo el análisis de los contenidos informativos de las radios generalistas, formato que en España se sustenta sobre una programación basada en gran parte en la información.

El corpus de análisis se decidió limitar a las noticias nacionales, correspondientes a la programación en cadena, difundidas por los programas informativos de mediodía de las cuatro emisoras: Hora 14 (Cadena SER), Mediodía COPE (Cadena COPE), Noticias Mediodía (Onda Cero) y 14 Horas (Radio Nacional de España-Radio 1). Entre las 14:00 y las 15:00 horas, según los datos EGM de la tercera ola de 2018 (AIMC, 2019), la radio generalista española presenta una audiencia total de 1.433 .000 oyentes. Aunque el programa de la cadena COPE excede a esa hora de emisión -según se explicará a continuación-, las audiencias, entre las dos y las tres de la tarde, se distribuyen de la siguiente forma: Hora 14 (SER), 493.000 oyentes; Mediodía COPE, 222.000; Noticias Mediodía (Onda Cero), 208.000; 14 horas (Radio Nacional de EspañaRadio 1), 159.000 . El $75,5 \%$ de la audiencia total de la radio generalista entre las $14: 00$ y las 15:00 horas sintoniza estos programas informativos. 
La conformación del corpus de análisis, a partir de las noticias difundidas en esta hora de programación en las cuatro grandes cadenas, obedece fundamentalmente a criterios informativos. Estos programas presentan una estructura clásica de programa informativo radiofónico con presencia de las diferentes secciones temáticas y de diversos géneros periodísticos (noticias, reportajes y, en algunos casos, también entrevistas y opinión). Los cuatro programas se configuran a modo de diario hablado en el que prevalecen los contenidos informativos, a diferencia de otros programas en los que la información ocupa menos tiempo que los contenidos de opinión. Concentran las informaciones más destacadas de la jornada hasta el mediodía, recogen, por tanto, el resultado del trabajo que los periodistas han realizado a lo largo de toda la mañana. Buena parte de estas noticias ya han sido avanzadas en los boletines de noticias previos. Por todas estas características, fueron considerados los programas más idóneos para realizar un estudio sistemático comparado sobre la utilización de las fuentes periodísticas en las noticias radiofónicas.

El trabajo de campo se desarrolló en el mes de septiembre porque constituye el inicio de la temporada radiofónica y acostumbra a ser un periodo denso desde la perspectiva informativa: diferentes instituciones retoman su actividad, se inician el curso parlamentario-político, escolar y judicial, y también comienzan buena parte de las competiciones deportivas.

La primera fase consistió en la escucha y grabación de los programas mencionados durante las semanas del 3 al 7 de septiembre de 2018 (Cadena SER y Cadena COPE) y del 10 al 14 del mismo mes (Onda Cero y Radio Nacional de España-Radio 1). Todas las noticias fueron transcritas para proceder al posterior análisis de contenido. Las piezas informativas constituyeron las unidades de análisis a partir de las que se identificaron las diferentes fuentes informativas referenciadas.

El protocolo de análisis de contenido, elaborado a partir de Bardin (2002) y Herscovitz (2007), se recoge en la Tabla I. Todas las variables definidas en este código se corresponden directamente con el tratamiento periodístico de las fuentes, objeto central de la investigación. Cada variable se asoció a una serie de valores que fueron asignados a partir de unas instrucciones de codificación. El análisis se orientó a identificar cada una de las fuentes utilizadas, clasificar las fuentes a partir de la taxonomía propuesta, y cuantificar las frecuencias de utilización para cada tipo de fuente, así como su distribución por las principales secciones temáticas. Las variables de análisis están ligadas directamente a las preguntas y objetivos de la investigación y a gran parte de los debates conceptuales presentes en el marco teórico-conceptual.

Se cuantificaron las unidades de cada tipología de fuente; las secciones temáticas en las que fueron utilizadas (política, sociedad, economía, cultura y deportes); las formas de mención: directa, indirecta, con declaraciones -corte de voz- o sin ellas; y el número de fuentes referenciadas en cada noticia. Este análisis sistemático de las fuentes no permitió tan solo cuantificar frecuencias, sino también estudiar el tratamiento informativo que se aplica con cada una de ellas y conocer cómo son utilizadas en cada sección.

Para establecer el análisis de los tipos de fuentes y sus diferencias de acceso a los informativos radiofónicos, se ha aplicado la siguiente propuesta de taxonomía de fuentes periodísticas utilizadas en el periodismo radiofónico (Kischinhevsky y Chagas, 2017). Esta clasificación también ha sido aplicada en una reciente investigación sobre las fuentes informativas utilizadas por las dos emisoras brasileñas con programación especializada en información: CBN y BandNews. (Chagas, 2019)

1. Oficiales - Titulares de cargos públicos y funcionarios de los poderes ejecutivo, legislativo y judicial en los ámbitos de la administración estatal, autonómica y local. También se incluye en esta categoría a los responsables de fundaciones públicas e instituciones educativas.

2. Empresariales - Representantes de los sectores comercial, financiero, industrial, corporaciones empresariales, consultorías y cualquier organización de ámbito privado.

3. Institucionales - Integrantes de organizaciones del tercer sector, movimientos sociales, organizaciones sindicales, organismos multilaterales.

4. Testimoniales - Testigos que han presenciado directamente hechos o acontecimientos y son seleccionados por esa condición, a partir del valor-noticia atribuido por los periodistas, para aportar su testimonio.

5. Populares - Ciudadanos que, en general, son representados en el informativo como víctimas de determinadas situaciones: injusticias, políticas públicas deficientes, delitos, etc.; o bien integrantes de la sociedad civil que se manifiestan para expresar reivindicaciones de cualquier tipo.

6. Especialistas - Profesionales con un reconocido saber científico o conocimiento específico sobre una determinada temática sobre la que se está desarrollando una cobertura periodística. 
Tabla I. Resumen protocolo de análisis de contenido

\begin{tabular}{|c|c|c|}
\hline & Variable & Valores Asociados \\
\hline 1 & Tipo de identificación & $\begin{array}{l}\text { 1. Mención directa } \\
\text { 2. Sin identificación o fuente velada } \\
\text { 3. Fuente parcialmente identificada }\end{array}$ \\
\hline 2 & $\begin{array}{l}\text { Tipología - Clasificación de la fuente a partir } \\
\text { de un listado de grupos sociales }\end{array}$ & $\begin{array}{l}\text { 1. Oficial } \\
\text { 2. Empresarial } \\
\text { 3. Institucional } \\
\text { 4. Testimonial } \\
\text { 5. Popular } \\
\text { 6. Especialista } \\
\text { 7. Celebridad }\end{array}$ \\
\hline 3 & $\begin{array}{l}\text { Número Total - Cantidad de fuentes distintas } \\
\text { incluidas en la noticia }\end{array}$ & $\begin{array}{l}\text { 0. Sin fuentes } \\
\text { 1. Una fuente } \\
\text { 2. Dos fuentes } \\
\text { 3. Tres fuentes } \\
\text { 4. Cuatro fuentes } \\
\text { 5. Cinco fuentes } \\
\text { 6. Más de cinco fuentes }\end{array}$ \\
\hline 4 & $\begin{array}{l}\text { Secciones temáticas - Distribución de } \\
\text { las fuentes referenciadas por secciones } \\
\text { temáticas }\end{array}$ & $\begin{array}{l}\text { 1. Política } \\
\text { 2. Sociedad } \\
\text { 3. Economía } \\
\text { 4. Cultura } \\
\text { 5. Deportes }\end{array}$ \\
\hline
\end{tabular}

7. Celebridades - Artistas, deportistas, comunicadores, en general, personas que desempeñan o han desempeñado actividades de gran reconocimiento social sobre las cuales se atribuyen valores variables valores-noticia.

Esta segmentación de fuentes ha sido aplicada con el objetivo de analizar la pluralidad y diversidad de las fuentes utilizadas en el periodismo radiofónico, así como de describir, clasificar y formular inferencias sobre la actuación periodística. La técnica cuantitativa del análisis de contenido ha permitido obtener un conjunto de datos objetivos y medibles, a partir de los cuales se han establecido los patrones de uso de cada fuente en relación con su contexto y en función de las secciones temáticas en las que son clasificadas las noticias.

Los datos de la distribución total de la muestra analizada se exponen en la Tabla II. La estructura del programa Mediodía COPE, durante la temporada 2018-2019, tras los comentarios editoriales iniciales, distribuía las noticias en dos bloques de 40 minutos: el primero de ellos entre las 13:00 horas a las 14:00, y el segundo, entre las 14:00 horas y las 15:00. Eso explica que el total de mi- nutos analizados sea superior para este programa de la cadena COPE. En el caso de los otros tres programas, se ha analizado la hora desde las 14:00 a las 15:00, en la que desarrollaron su contenido informativo. El número de horas de escucha ha ascendido, por tanto, a las 21 horas y 40 minutos. Las desconexiones de información autonómica y local analizadas han correspondido con el ámbito territorial de la Comunidad de Madrid y su capital.

El análisis durante una semana -de lunes a viernes- de los cuatro programas informativos permitió extraer 227 unidades de análisis diferentes, integradas por noticias y otros contenidos informativos (reportajes y entrevistas). Tras la transcripción de todas ellas, se identificaron un total de 383 fuentes informativas que constituyeron el objeto de estudio de esta investigación, cifra que se considera suficientemente significativa para poder identificar tendencias en la utilización de las fuentes por parte de los periodistas. Entre las variables de análisis ya descritas, se observó, con especial atención, el número de fuentes presentes en cada noticia para comprobar si había sido aplicado el contraste de fuentes en la construcción de la información. 


\section{RESULTADOS Y DISCUSIÓN}

\subsection{Identificación de fuentes y utilización de declaraciones}

La primera variable del estudio fue el grado de identificación de las fuentes informativas utilizadas en las noticias que conforman el corpus del análisis. La correcta mención de las fuentes se considera una práctica periodística vinculada con la calidad informativa. Casero-Ripollés y López (2013) aportan cinco indicadores internos para valorar la calidad de la información: estatus profesional, verificación, relevancia, reducción de incertidumbre y transparencia, este último asociado directamente a la identificación de las fuentes.

Los periodistas radiofónicos identifican de una forma precisa el $95 \%$ de las fuentes utilizadas, un porcentaje muy elevado. Hora 14 de la Cadena SER presentó el mayor número de fuentes sin identificación -un 6,8\%-de los cuatro programas analizados, cifra que puede ser considerada baja (Tabla III).

Las declaraciones directas de las fuentes constituyen un recurso narrativo esencial en el periodismo radiofónico. El $84,9 \%$ de las fuentes mencio- nadas se acompañaron de sus respectivos audios (Tabla IV). La inclusión de cortes de voz o fragmentos de entrevistas aportan credibilidad a la noticia y condicionan la propia estructura y redacción del relato periodístico.

\subsection{Fuentes utilizadas por noticia}

Para el análisis de esta variable se excluyeron todas las menciones en las que el periodista era la propia fuente de la información. En los cuatro programas objeto de estudio se puede concluir que la mayoría de las noticias hacen referencia tan solo a una fuente, sin aportar ningún tipo de verificación. Los periodistas radiofónicos no contrastan, al menos con dos fuentes, el $45,8 \%$ de sus informaciones y no mencionan ninguna fuente en el $2,6 \%$ de ellas (Tabla V). Estos resultados presentan altos niveles de coincidencia con los obtenidos en investigaciones previas sobre el uso de fuentes periodísticas en España (Berganza y Chaparro, 2012; Rodríguez-Rey y otros, 2015; Pérez Curiel y otros, 2015; Mayoral, 2005). Tomando como referencia los resultados de todos estos estudios, el porcentaje de noticias con una única fuente oscila entre el $55,5 \%$ (Berganza y Chaparro, 2012) y el $43,1 \%$ (Rodríguez Rey y otros, 2015).

Tabla II. $\mathrm{N}^{\circ}$ total de noticias/no de fuentes/ horas analizadas por programas

\begin{tabular}{|l|c|c|c|}
\hline $\begin{array}{c}\text { Programas } \\
\text { Informativos }\end{array}$ & $\begin{array}{c}\text { Horas totales de } \\
\text { programación } \\
\text { analizada }\end{array}$ & $\begin{array}{c}\text { Número total de } \\
\text { noticias/contenidos } \\
\text { (unidades de análisis) }\end{array}$ & $\begin{array}{c}\text { Total de fuentes } \\
\text { informativas } \\
\text { mencionadas }\end{array}$ \\
\hline Hora 14. SER & 2h30min & 67 & 117 \\
\hline Mediodía COPE. & 3 h20min & 45 & 92 \\
\hline $\begin{array}{l}\text { Noticias Mediodía. } \\
\text { Onda Cero }\end{array}$ & $3 \mathrm{~h} 20 \mathrm{~min}$ & 54 & 88 \\
\hline 14 Horas. RNE-Radio 1 & $5 \mathrm{~h}$ & 61 & 86 \\
\hline TOTAL & $\mathbf{1 4 h 1 0 m i n}$ & $\mathbf{2 2 7}$ & $\mathbf{3 8 3}$ \\
\hline
\end{tabular}

Tabla III. Identificación de las Fuentes

\begin{tabular}{|l|c|c|c|}
\hline \multicolumn{1}{|c|}{ Emisora } & $\begin{array}{c}\text { Identificación completa } \\
\text { (mención directa) }\end{array}$ & Sin identificación & $\begin{array}{c}\text { Parcialmente } \\
\text { identificada }\end{array}$ \\
\hline Hora 14. SER & $105(89,7 \%)$ & $8(6,8 \%)$ & $4(3,4 \%)$ \\
\hline Mediodía COPE & $88(95,7 \%)$ & $2(2,2 \%)$ & $2(2,2 \%)$ \\
\hline $\begin{array}{l}\text { Noticias Mediodía. } \\
\text { Onda Cero }\end{array}$ & $86(97,7 \%)$ & $1(1,1 \%)$ & $1(1,1 \%)$ \\
\hline 14 Horas. RNE-Radio 1 & $85(98,8 \%)$ & $1(1,2 \%)$ & $0(0,0 \%)$ \\
\hline \multicolumn{1}{|c|}{ TOTAL } & $\mathbf{3 6 4 ( 9 5 , 0 \% )}$ & $\mathbf{1 2}(\mathbf{3}, \mathbf{1} \%)$ & $\mathbf{7}(\mathbf{1}, \mathbf{8} \%)$ \\
\hline
\end{tabular}


Tabla IV. Utilización de declaraciones directas (cortes de voz)

\begin{tabular}{|l|c|c|}
\hline \multicolumn{1}{|c|}{ Emisora } & $\begin{array}{c}\text { Con cortes } \\
\text { de voz }\end{array}$ & $\begin{array}{c}\text { Sin cortes } \\
\text { de voz }\end{array}$ \\
\hline Hora 14. SER & $96(82,1 \%)$ & $21(17,9 \%)$ \\
\hline Mediodía COPE. & $78(84,8 \%)$ & $14(15,2 \%)$ \\
\hline $\begin{array}{l}\text { Noticias Mediodía. } \\
\text { Onda Cero }\end{array}$ & $79(89,8 \%)$ & $9(10,2 \%)$ \\
\hline $\begin{array}{l}\text { 14 Horas. RNE- } \\
\text { Radio 1 }\end{array}$ & $72(83,7 \%)$ & $14(16,3 \%)$ \\
\hline \multicolumn{1}{|c|}{ TOTAL } & $\mathbf{3 2 5}(84,9 \%)$ & $\mathbf{5 8}(15,1 \%)$ \\
\hline
\end{tabular}

El programa Hora 14 de la Cadena SER es el que contrasta sus informaciones con un menor número de fuentes. El $49,3 \%$ de sus noticias mencionan una única fuente informativa. Las noticias que citan dos fuentes representaron el $38,8 \%$ y tres el $9 \%$. La diferencia es mínima respecto a Mediodía $C O P E$, que también presenta un porcentaje muy elevado -el $48,9 \%$ - de noticias sustentadas en una sola fuente informativa. En el $24,4 \%$ de sus informaciones se pueden identificar dos fuentes. 14 Horas de RNE y Noticias Mediodía de Onda Cero presentan un $42,6 \%$ de noticias con fuente única, mientras que los porcentajes de informaciones con dos fuentes son del $32,8 \%$ y el $31,5 \%$, respectivamente. En el caso de Onda Cero sorprende el elevado porcentaje $(5,6 \%)$ de noticias que no referencian ni una sola fuente informativa (Tabla $\mathrm{V}$ ).

Si observamos los porcentajes a la inversa, es decir, por el número de noticias que mencionan más de una fuente informativa, el programa de la cadena pública $R N E$ es el que más contrasta sus informaciones, con un 55,7\%; seguido de Noticias
Mediodía de Onda Cero, 51,85\%; Hora 14 de Cadena SER y Mediodía COPE presentan porcentajes inferiores, un $49,25 \%$ y un $48,8 \%$, respectivamente.

Es necesario advertir que la utilización de más de una fuente informativa no garantiza que se produzca el contrapunto o la diversidad necesaria para que en el contenido de la noticia se reflejen los diferentes enfoques o intereses de los agentes implicados en el acontecimiento.

\subsection{Tipología de fuentes}

El análisis de la distribución de las fuentes, en función de su tipología, revela una utilización preferente de las fuentes oficiales respecto a cualquier otra categoría de fuente. Se confirma que el criterio de selección de las fuentes está condicionado por la jerarquización de la credibilidad de las fuentes (Traquina, 2005) y la estructuración de las relaciones de confianza (Reich, 2011). En tres de los cuatro programas analizados las fuentes de carácter oficial son las más utilizadas: Noticias Mediodía de Onda Cero es el programa en el que mayor presencia tienen este tipo de fuentes, representan el $68,2 \%$ del total de las fuentes identificadas. Un porcentaje tan elevado denota una excesiva dependencia de las fuentes oficiales. Le siguen Hora 14 de Cadena SER, el $52,1 \%$ de sus fuentes son oficiales; y 14 Horas de $R N E$, con el $47,7 \%$. Los periodistas de Mediodía COPE recurren de una forma bastante más moderada a las fuentes oficiales, ya que estas representan el $31,5 \%$ del total de fuentes referenciadas, incluso por debajo del porcentaje de utilización de fuentes populares (37\%) (Tabla VI). Si bien, esa mayor presencia de fuentes populares se circunscribe principalmente a temáticas de la sección de sociedad-educación: inicio de curso escolar, tráfico, desempleo y conflictos laborales.

Tabla V. Número de fuentes utilizadas por noticia

\begin{tabular}{|c|c|c|c|c|c|c|}
\hline Emisora & Sin Fuentes & 1 fuente & 2 fuentes & 3 fuentes & 4 fuentes & $\begin{array}{c}5 \text { fuentes o } \\
\text { más }\end{array}$ \\
\hline Hora 14. SER & $\begin{array}{c}1 \\
1,5 \%\end{array}$ & $\begin{array}{c}33 \\
49,3 \%\end{array}$ & $\begin{array}{c}26 \\
38,8 \%\end{array}$ & $\begin{array}{c}6 \\
9,0 \%\end{array}$ & $\begin{array}{c}0 \\
0,0 \%\end{array}$ & $\begin{array}{c}1 \\
1,5 \%\end{array}$ \\
\hline Mediodía COPE & $2,2 \%$ & $\begin{array}{c}22 \\
48,9 \%\end{array}$ & $\begin{array}{c}11 \\
24,4 \%\end{array}$ & $\begin{array}{c}6 \\
13,3 \%\end{array}$ & $\begin{array}{c}3 \\
4,7 \%\end{array}$ & $\begin{array}{c}2 \\
4,4 \%\end{array}$ \\
\hline $\begin{array}{l}\text { Noticias Mediodía } \\
\text { Onda Cero }\end{array}$ & $\begin{array}{c}3 \\
5,6 \%\end{array}$ & $\begin{array}{c}23 \\
42,6 \%\end{array}$ & $\begin{array}{c}17 \\
31,5 \%\end{array}$ & $\begin{array}{c}7 \\
13,0 \%\end{array}$ & $\begin{array}{c}3 \\
5,6 \%\end{array}$ & $\begin{array}{c}1 \\
1,9 \%\end{array}$ \\
\hline $\begin{array}{l}14 \text { Horas } \\
\text { RNE-Radio } 1\end{array}$ & $\begin{array}{c}1 \\
1,6 \%\end{array}$ & $\begin{array}{c}26 \\
42,6 \%\end{array}$ & $\begin{array}{c}20 \\
32,8 \%\end{array}$ & $\begin{array}{c}9 \\
14,8 \%\end{array}$ & $\begin{array}{c}1 \\
1,6 \%\end{array}$ & $\begin{array}{c}4 \\
6,6 \%\end{array}$ \\
\hline TOTAL & $\begin{array}{c}6 \\
2,6 \%\end{array}$ & $\begin{array}{c}104 \\
45,8 \%\end{array}$ & $\begin{array}{c}74 \\
32,6 \%\end{array}$ & $\begin{array}{c}28 \\
12,3 \%\end{array}$ & $\begin{array}{c}7 \\
3,1 \%\end{array}$ & $\begin{array}{c}8 \\
3,5 \%\end{array}$ \\
\hline
\end{tabular}


Las fuentes oficiales mantienen su hegemonía, también en este programa de Cadena COPE, en las noticias relacionadas con asuntos políticos.

A partir de los resultados obtenidos, es posible afirmar que las voces oficiales dominan el relato periodístico de los cuatro programas radiofónicos sobre la actualidad política en España, principalmente a partir de los que se ha considerado periodismo de convocatoria (Pérez-Curiel y otros, 2015) vinculado a la actuación de los gobiernos español, autonómico y local. Estas fuentes prácticamente monopolizan las noticias que se generan a partir de la actividad parlamentaria, de las que se informa aplicando sobre todo un periodismo de carácter declarativo.

La preferencia por utilizar fuentes autorizadas domina las rutinas profesionales periodísticas en la radio española, así se manifiesta con el uso intensivo del otro tipo de fuente que podemos calificar como "autorizada" -además de las oficiales-: el clasificado en la taxonomía como fuentes institucionales. Este tipo de fuente también es de las más utilizadas en los cuatro programas (Tabla VI). Su presencia es transversal a todas las secciones temáticas, se recurre a ella en noticias sobre política, economía, cultura, educación y deportes. Esta profusión de fuentes oficiales en las noticias radiofónicas evidencia la elevada profesionalización de la comunicación y de las relaciones con los medios de comunicación que se ha producido en instituciones políticas, sociales, culturales, deportivas, educativas, empresariales o sindicales, con el objetivo de controlar el relato informativo de aquellos acontecimientos que protagonizan o pueden estar en el ámbito de sus intereses organizacionales. En algunas de las noticias analizadas se llega a explicitar por parte de los propios informadores la actitud proactiva de algunos de estos agentes para entrar en contacto con los periodistas para ofrecer su versión de los acontecimientos.

\subsection{Distribución de las fuentes por secciones temáticas}

Las noticias que se encuadran en la sección de política son las que concentran el mayor número de fuentes. El $65 \%$ del total de las fuentes utilizadas por el programa Hora 14 de la Cadena SER se localizan en noticias de temática política, en el caso de Noticias Mediodía de Onda Cero, el 52\%. La mayor parte de estas fuentes se referencian en noticias vinculadas a la actividad parlamentaria y de los gobiernos en sus distintos ámbitos territoriales. Estos son los dos programas con mayor presencia de noticias de carácter político. En esta misma sección se ubica el $25 \%$ del total de fuentes utilizadas en Mediodía COPE.

En el programa 14 Horas de Radio Nacional de España también predomina la información política, aunque con una menor diferencia que en los dos anteriores, ya que en este informativo tienen mayor presencia noticias de otras temáticas. Respecto a la utilización de las fuentes, el 38,4\% de las que son referenciadas se localizan en noticias políticas, frente al 29,1\% presentes en informaciones sobre sociedad (Tabla VII).

Informar sobre los acontecimientos que configuran la dinámica política es la gran prioridad en la información radiofónica que integra estos programas. En las semanas en las que se ha realizado el trabajo de campo del estudio los ejes que dominaron la actualidad informativa fueron las decisiones e iniciativas del gobierno de Pedro Sánchez, reacciones de los principales partidos de la oposición y las novedades sobre el conflicto político en Cataluña.

Tabla VI. Fuentes utilizadas según tipología

\begin{tabular}{|c|c|c|c|c|c|c|c|c|}
\hline Emisora & Oficiales & Populares & $\begin{array}{c}\text { Especialis- } \\
\text { tas }\end{array}$ & $\begin{array}{l}\text { Empresa- } \\
\text { riales }\end{array}$ & $\begin{array}{c}\text { Institucio- } \\
\text { nales }\end{array}$ & $\begin{array}{l}\text { Testimo- } \\
\text { niales }\end{array}$ & $\begin{array}{l}\text { Celebrida- } \\
\text { des }\end{array}$ & $\begin{array}{c}\text { Sin } \\
\text { Identifica- } \\
\text { ción }\end{array}$ \\
\hline Hora 14 SER & $\begin{array}{c}61 \\
52,1 \%\end{array}$ & $\begin{array}{c}12 \\
10,3 \%\end{array}$ & $\begin{array}{c}4 \\
3,4 \%\end{array}$ & $\begin{array}{c}6 \\
5,1 \%\end{array}$ & $\begin{array}{c}13 \\
11,1 \%\end{array}$ & $\begin{array}{c}7 \\
6,0 \%\end{array}$ & $\begin{array}{c}6 \\
5,1 \%\end{array}$ & $\begin{array}{c}8 \\
6,8 \%\end{array}$ \\
\hline $\begin{array}{l}\text { Mediodía } \\
\text { COPE }\end{array}$ & $\begin{array}{c}29 \\
31,5 \%\end{array}$ & $\begin{array}{c}33 \\
35,9 \%\end{array}$ & $\begin{array}{c}3 \\
3,3 \%\end{array}$ & $\begin{array}{c}4 \\
4,3 \%\end{array}$ & $\begin{array}{c}12 \\
13,0 \%\end{array}$ & $\begin{array}{c}3 \\
3,3 \%\end{array}$ & $\begin{array}{c}5 \\
5,4 \%\end{array}$ & $\begin{array}{c}3 \\
3,3 \%\end{array}$ \\
\hline $\begin{array}{l}\text { Noticias } \\
\text { Mediodía } \\
\text { Onda Cero }\end{array}$ & $\begin{array}{c}60 \\
68,2 \%\end{array}$ & $\begin{array}{c}0 \\
0,0 \%\end{array}$ & $\begin{array}{c}1 \\
1,1 \%\end{array}$ & $\begin{array}{c}2 \\
2,3 \%\end{array}$ & $\begin{array}{c}15 \\
17,0 \%\end{array}$ & $\begin{array}{c}0 \\
0,0 \%\end{array}$ & $\begin{array}{c}9 \\
10,2 \%\end{array}$ & $\begin{array}{c}1 \\
1,1 \%\end{array}$ \\
\hline $\begin{array}{l}14 \text { Horas } \\
\text { RNE-Radio } 1\end{array}$ & $\begin{array}{c}41 \\
47,7 \%\end{array}$ & $\begin{array}{c}1 \\
1,2 \%\end{array}$ & $\begin{array}{c}4 \\
4,7 \%\end{array}$ & $\begin{array}{c}6 \\
7,0 \%\end{array}$ & $\begin{array}{c}19 \\
22,1 \%\end{array}$ & $\begin{array}{c}1 \\
1,2 \%\end{array}$ & $\begin{array}{c}13 \\
15,1 \%\end{array}$ & $\begin{array}{c}1 \\
1,2 \%\end{array}$ \\
\hline TOTAL & $\begin{array}{c}191 \\
49,9 \%\end{array}$ & $\begin{array}{c}46 \\
12 \%\end{array}$ & $\begin{array}{c}12 \\
3,1 \%\end{array}$ & $\begin{array}{c}18 \\
4,7 \%\end{array}$ & $\begin{array}{c}59 \\
15,4 \%\end{array}$ & $\begin{array}{c}11 \\
2,9 \%\end{array}$ & $\begin{array}{c}33 \\
8,6 \%\end{array}$ & $\begin{array}{c}13 \\
3,4 \%\end{array}$ \\
\hline
\end{tabular}


El programa Mediodía COPE dedica mayor atención que sus competidores a los temas sociales, si atendemos a las fuentes utilizadas. El 46,7\% de ellas se localizan en noticias de sociedad. Este informativo utiliza mensajes de voz que sus oyentes envían por Whatsapp. Este sistema de interacción con la audiencia permite a los oyentes expresar sus opiniones e incluso erigirse en fuente informativa ante algunos acontecimientos, que suelen circunscribirse a informaciones sobre sociedad.

Se registran diferencias importantes en la utilización de las fuentes informativas entre las diferentes secciones. Las noticias de política y sociedad referencian un mayor número de fuentes que las de temática económica, cultural o deportiva. Son diversos los factores que pueden incidir en esta distribución desigual en el uso de las fuentes: la estructura de la redacción y la especialización de sus profesionales, las prioridades informativas de la dirección de estos programas y la naturaleza del contenido de las noticias de estas secciones.

En la sección política se utilizan 2,4 fuentes de promedio por noticia en el caso de Onda Cero; 2,3 en Hora 14 de Cadena SER; 2,1 en Mediodía COPE; y 1,9 en 14 Horas de RNE. En Sociedad, el programa de COPE es el que más contrasta sus noticias (3,3 fuentes por información); 2,3 en el caso de $R N E ; 1,7$ en Hora 14 de SER; y 0,8 en el programa Noticias Mediodía, de Onda Cero. Según se puede observar, la disparidad de resultados entre programas es mayor en esta variable de estudio que en las anteriores, responde a las diferentes prácticas profesionales desarrolladas en las redacciones.

En las noticias de temática económica se refleja con claridad esta variabilidad entre programas. Noticias Mediodía de Onda Cero menciona 3 fuentes de promedio por noticia en esta sección; Mediodía COPE identifica 1,5 fuentes; mientras que Hora 14 de SER y 14 Horas de RNE citan tan solo 0,8 fuentes.

Las secciones de cultura y deportes son las que incluyen un menor número de fuentes. En las noticias culturales el programa de COPE menciona 1,6 fuentes de promedio por información; Noticias Mediodía de Onda Cero, 1 fuente. 14 Horas de RNE y Hora 14 de SER ni siquiera llegan a una fuente: 0,9 y 0,6, respectivamente. En deportes, 1,4 fuentes por noticia en el programa de Onda Cero; 0,8 en el caso del de RNE; 0,75, cadena SER; y 0,2 en COPE.

Tabla VII. Distribución de fuentes por secciones temáticas

\begin{tabular}{|l|c|c|c|c|c|}
\hline \multicolumn{1}{|c|}{ Emisora } & Política & Sociedad & Economía & Cultura & Deportes \\
\hline \multirow{2}{*}{ Hora 14 SER } & 76 & 28 & 4 & 6 & 3 \\
& $65,0 \%$ & $23,9 \%$ & $3,4 \%$ & $5,1 \%$ & $2,6 \%$ \\
\hline \multirow{2}{*}{ Mediodía COPE } & 23 & 43 & 17 & 8 & 1 \\
& $25 \%$ & $46,7 \%$ & $8,5 \%$ & $8,7 \%$ & $1,1 \%$ \\
\hline Noticias Mediodía & 46 & 14 & 9 & 5 & 14 \\
Onda Cero & $52,3 \%$ & $15,9 \%$ & $10,2 \%$ & $5,7 \%$ & $15,9 \%$ \\
\hline 14 Horas & 33 & 25 & 8 & 11 & 9 \\
RNE-Radio 1 & $38,4 \%$ & $29,1 \%$ & $9,3 \%$ & $12,8 \%$ & $10,5 \%$ \\
\hline \multirow{2}{*}{ TOTAL } & $\mathbf{1 7 8}$ & $\mathbf{1 1 0}$ & $\mathbf{3 8}$ & $\mathbf{3 0}$ & $\mathbf{2 7}$ \\
\hline
\end{tabular}

Tabla VIII. Promedio de fuentes utilizadas en cada noticia por secciones temáticas

\begin{tabular}{|l|c|c|c|c|c|}
\hline \multicolumn{1}{|c|}{ Emisora } & Política & Sociedad & Economía & Cultura & Deportes \\
\hline $\begin{array}{l}\text { Hora 14. Cadena } \\
\text { SER }\end{array}$ & 2,3 & 1,7 & 0,8 & 0,6 & 0,75 \\
\hline Mediodía COPE & 2,1 & 3,3 & 1,5 & 1,6 & 0,2 \\
\hline $\begin{array}{l}\text { Noticias Mediodía } \\
\text { Onda Cero }\end{array}$ & 2,4 & 0,8 & 3 & 1 & 1,4 \\
\hline $\begin{array}{l}\text { 14 Horas } \\
\text { RNE-Radio1 }\end{array}$ & 1,9 & 2,3 & 0,8 & 0,9 & 0,8 \\
\hline \multicolumn{1}{|c|}{ TOTAL } & $\mathbf{2 , 2 2}$ & $\mathbf{1 , 9 2}$ & $\mathbf{1 , 3 1}$ & $\mathbf{0 , 9 6}$ & $\mathbf{0 , 9}$ \\
\hline
\end{tabular}


El análisis de las noticias por secciones temáticas indica que, en el periodo estudiado, Hora 14 de la Cadena SER presenta el mayor porcentaje de informaciones políticas $(49.3 \%$ del total de noticias), seguido por Noticias Mediodía de Onda Cero (35.2\%), 14 Horas de RNE (27,9\%) y Mediodía COPE (24,4\%). Estos dos últimos informativos ofrecen una atención más equilibrada entre las secciones de política, sociedad y economía. Sociedad es la que registra una menor diferencia porcentual entre las cuatro emisoras (Noticias Mediodía Onda Cero: 31,5\%; Mediodía COPE: 28,9\%; Hora 14. Cadena SER: $23,9 \%$; 14 Horas RNE: 18\%). Los programas informativos de la Cadena COPE $(24,4 \%)$ y $R N E$ $(16,4 \%)$ son los que recogen un mayor porcentaje de noticias económicas. El informativo de $R N E$ es el que más noticias incluye sobre actualidad cultural. En el caso de las informaciones deportivas, destaca el reducido número de noticias del programa Hora 14 de la Cadena SER respecto a sus competidores. Sin duda, esa baja presencia del deporte se debe a que, inmediatamente a continuación de Hora 14, la cadena emite SER Deportivos, un programa de 55 minutos dedicado a la actualidad deportiva. Es preciso señalar que, a partir de los resultados extraídos del periodo objeto de estudio, se percibe que estos programas dirigen su atención informativa principalmente hacia la actualidad política -con excepción de Noticias Mediodía de Onda Cero-; pero los datos de esta variable registran importantes cambios, en función de los diferentes periodos de análisis, provocados por los propios ritmos de la actualidad.

\section{CONCLUSIONES}

En términos generales, los resultados de la investigación corroboran las hipótesis de las que partía este estudio: los periodistas radiofónicos utilizan un número reducido de fuentes informativas en la elaboración de sus noticias; las fuentes ofi- ciales son hegemónicas en la articulación de la mayor parte de noticias; y, por último, los ciudadanos apenas tienen presencia como fuentes en noticias de temática política o económica, su participación, en todo caso, se limita a determinadas informaciones de temática social.

1.- Este estudio planteaba como primer objetivo específico verificar si los periodistas radiofónicos están aplicando criterios profesionales, basados en el contraste y la diversidad, en la gestión de las fuentes. Tras el análisis de los resultados, se evidencia una excesiva dependencia de fuentes informativas únicas en gran número de las noticias. Es posible que los periodistas hayan utilizado otras fuentes, sin mencionarlas, en algunas de las noticias que han integrado el corpus de estudio, aunque, en ese caso, tampoco se estarían respetando los estándares profesionales que instan a indicar la procedencia de las informaciones. En todo caso, se observan deficiencias importantes en la tarea periodística del contraste de fuentes, con las múltiples implicaciones que ello puede acarrear para la calidad y credibilidad de las noticias. Por el contrario, se constata una identificación precisa para la práctica totalidad de las fuentes citadas por los periodistas.

Los resultados de este estudio exploratorio son consistentes con los obtenidos en investigaciones previas sobre la utilización de las fuentes informativas, la mayoría de ellas centradas en el ámbito de la prensa escrita. A partir de las variables analizadas, no se aprecian diferencias significativas o rasgos específicos en lo referido a la utilización de las fuentes informativas por parte de los periodistas radiofónicos respecto a los profesionales de los otros medios. Las problemáticas y posibles deficiencias parecen compartidas por toda la profesión periodística.

Tabla IX. Noticias por secciones temáticas

\begin{tabular}{|c|c|c|c|c|c|}
\hline Emisora & Política & Sociedad & Economía & Cultura & Deportes \\
\hline Hora 14 SER & $\begin{array}{c}33 \\
49,3 \%\end{array}$ & $\begin{array}{c}16 \\
23,9 \%\end{array}$ & $\begin{array}{l}5 \\
7,5 \%\end{array}$ & $\begin{array}{c}9 \\
13,4 \%\end{array}$ & $\begin{array}{c}4 \\
6,0 \%\end{array}$ \\
\hline Mediodía COPE & $\begin{array}{c}11 \\
24,4 \%\end{array}$ & $\begin{array}{c}13 \\
28,9 \%\end{array}$ & $\begin{array}{c}11 \\
24,4 \%\end{array}$ & $\begin{array}{c}5 \\
11,1 \%\end{array}$ & $\begin{array}{c}5 \\
11,1 \%\end{array}$ \\
\hline $\begin{array}{l}\text { Noticias Mediodía } \\
\text { Onda Cero }\end{array}$ & $\begin{array}{c}19 \\
35,2 \%\end{array}$ & $\begin{array}{c}17 \\
31,5 \%\end{array}$ & $\begin{array}{c}3 \\
5,6 \%\end{array}$ & $\begin{array}{c}5 \\
9,3 \%\end{array}$ & $\begin{array}{c}10 \\
18,5 \%\end{array}$ \\
\hline $\begin{array}{l}14 \text { Horas } \\
\text { RNE-Radio } 1\end{array}$ & $\begin{array}{c}17 \\
27,9 \%\end{array}$ & $\begin{array}{c}11 \\
18,0 \%\end{array}$ & $\begin{array}{c}10 \\
16,4 \%\end{array}$ & $\begin{array}{c}12 \\
19,7 \%\end{array}$ & $\begin{array}{c}11 \\
18,0 \%\end{array}$ \\
\hline TOTAL & $\begin{array}{c}80 \\
35,2 \%\end{array}$ & $\begin{array}{c}57 \\
25,1 \%\end{array}$ & $\begin{array}{c}29 \\
12,8 \%\end{array}$ & $\begin{array}{c}31 \\
13,7 \%\end{array}$ & $\begin{array}{c}30 \\
13,2 \%\end{array}$ \\
\hline
\end{tabular}


La utilización de fuentes únicas denota una notable pasividad en la construcción de las noticias. La falta de diversificación en la procedencia de los datos que sustentan la noticia genera importantes desequilibrios entre voces y agentes que tienen un acceso privilegiado a los medios periodísticos, frente a otros a los que les resulta muy complicado encontrar un espacio para dar a conocer su visión e interpretación de los acontecimientos.

La escasez de fuentes también podría indicar carencias en la formación periodística relacionadas con la búsqueda, gestión y explotación de fuentes de información pertinentes y de calidad, especialmente en el caso de las especializadas. Esta carencia profesional podría paliarse, al menos en parte, fortaleciendo en las redacciones sinergias entre los perfiles profesionales de periodistas y documentalistas, estos últimos por su condición de expertos en la gestión de fuentes y obtención de datos, con el objetivo de sustentar las noticias en un mayor número de recursos informativos y fuentes complementarias.

2.- Identificar posibles preferencias en el uso de las fuentes por parte de los periodistas, además de analizar las tipologías de fuentes más utilizadas por secciones, constituyó el segundo objetivo específico de esta investigación. Según los datos obtenidos, se puede apreciar que la profesionalización de las fuentes -su capacidad para articular y estructurar institucionalmente la comunicación- es uno de los factores que condicionan las posibilidades reales de los agentes sociales y políticos para lograr una mayor presencia en los contenidos de los medios de comunicación.

Se confirma que el periodismo radiofónico mantiene una relación estratégica con fuentes supuestamente fiables para el periodista -en su gran mayoría de carácter oficial e institucional-, hasta el extremo de generar una creciente dependencia en las propias rutinas profesionales. Estos agentes tienden a monopolizar, o al menos dominar, el relato de gran parte de las noticias, eso explica el elevado número de noticias que recurren tan solo a una o dos fuentes informativas diferentes. La capacidad de estos agentes de articular sus propios mensajes comunicativos -siempre formulados en defensa de sus intereses-, así como de atender con rapidez las peticiones informativas de los periodistas, les permite dominar gran parte del discurso informativo sobre los acontecimientos que les conciernen e incluso influir en la construcción de la llamada agenda mediática. La preferencia por estas fuentes no se realiza tan solo por la mayor credibilidad que los periodistas les puedan atribuir, influyen factores como la facilidad de acceso, las relaciones profesionales interpersonales que se establecen con ellas y la posibilidad de recabar datos útiles para la redacción de las informaciones.

Esta hegemonía de las fuentes oficiales e institucionales se genera a partir de la pasividad de los propios periodistas que relajan sus prácticas de verificación y contraste de la información ante una mayor credibilidad otorgada a la fuente profesionalizada. Estas fuentes tienen la posibilidad de contextualizar los acontecimientos, construyendo sobre ellos lo que podemos denominar una metanarrativa interesada. El contrapunto a este dominio de un tipo de fuentes es la presencia restringida de otras voces que el periodista considera problemáticas o alternativas, y que en muchos casos son de más difícil acceso. Ideas como la autonomía o la independencia periodística parecen quebrarse ante las deficiencias identificadas en la selección y utilización de las fuentes informativas.

Resulta necesario acometer en el futuro investigaciones, que permitan conocer en profundidad las causas de esas disfunciones en el periodismo, a partir del empleo de otras técnicas metodológicas como la observación participante o las entrevistas en profundidad. Son numerosas las nuevas preguntas de investigación que surgen a partir de los resultados obtenidos: ¿Cuáles son las causas de que los periodistas radiofónicos utilicen pocas fuentes en sus noticias? ¿Qué factores de las condiciones laborales o el entorno organizacional inciden más en las rutinas profesionales de los periodistas en relación con la gestión de fuentes? ¿Cómo atribuyen la credibilidad a las diferentes fuentes?

3.- También en relación con el segundo objetivo, se observa cierta correlación entre la temática de las noticias y el número de fuentes utilizadas. Si bien se registran importantes disparidades entre los programas analizados, las informaciones de política y sociedad incluyen un mayor número de fuentes que las noticias de economía, cultura o deportes; lo que sugiere una mayor atención de los profesionales hacia este tipo de contenidos y probablemente una estrategia más proactiva por parte de las fuentes asociadas a esas temáticas, que buscan influir en el relato informativo. 
4.- Por último, el tercer objetivo de la investigación buscaba indagar en las fórmulas de participación que estos programas informativos habilitan para que los ciudadanos también puedan intervenir como fuentes, en particular nos interesaba conocer si se están utilizando redes sociales o aplicaciones de mensajería instantánea para ello.

La utilización de la interacción con la audiencia, a través de aplicaciones de mensajería instantánea -como en el caso de la cadena COPE-, se muestra como una fórmula que posibilita la inclusión de fuentes populares, si bien eso necesariamente no implica una mayor diversidad de voces en las temáticas centrales de los informativos. El ciudadano común, excepto ante acontecimientos muy concretos de los que ha podido ser testigo directo, no tiene suficientes posibilidades de participar de las informaciones o de opinar sobre las grandes cuestiones de la política o la economía. En esas secciones siempre prevalecen las fuentes oficiales, institucionales, especializadas y empresariales. Los resultados de esta investigación señalan a que las fuentes populares alcanzan su mayor presencia en las noticias de sociedad, en particular en noticias relacionadas con el tráfico, la educación y los fenómenos meteorológicos. Por el momento, la interacción con la audiencia mantiene un carácter bastante restringido y superficial en el ámbito de los informativos radiofónicos.

\section{REFERENCIAS}

AIMC (2019). Marco general de los medios en España. Disponible en: https://www.aimc.es/a1mc-c0nt3nt/ uploads/2019/01/marco19.pdf [Fecha de consulta: 25/08/2019].

Alsina, M. R. (1993). La construcción de la noticia. (2a ed.) Barcelona: Paidós.

Amado, A.; Waisbord, S. (2018). Journalists and Media Ownership: Practices and Professional Conditions of Argentine Journalism. Brazilian Journalism Research, 14 (2), 364-388. https://doi.org/10.25200/BJR. v14n2.2018.1090

Anderson, C. W.; Bell, E.; Shirky, C. (2013.) Jornalismo pós-industrial: adaptando-se ao presente. Revista de Jornalismo ESPM, no 5, 30-89.

Bardin, L. (2002). Análisis de contenido (3a ed.) Madrid: Akal.

Berganza Conde, R.; Chaparro Domínguez, M. A. (2012). El rigor en la prensa: principales características y diferencias en el uso de las fuentes en los periódicos gratuitos y de pago. ZER, 17 (32), 29-49. https://www. ehu.eus/ojs/index.php/Zer/article/view/6552/5982 [Fecha de consulta: 12/06/2019].

Berganza Conde, R.; Herrero-Jiménez, B.; Gómez-Montero, E. L. (2018). ¿Quiénes son los periodistas españoles? Perfiles profesionales y transformaciones en la profesión. Brazilian Journalism Research, 14 (2), 330355. https://doi.org/10.25200/BJR.v14n2.2018.1077

Berelson, B. (1984). Content Analysis in communication research. N.York: Hafner.

Bratton, B. (2015). The Stack: OnSoftwareandSovereignty. Cambridge, MA: The MIT Press. http://dx.doi. org/10.7551/mitpress/9780262029575.001.0001

Breed, W. (1999). Controle social na redação: uma análise funcional. En: Traquina, N. (Org.). Jornalismo: questões, teorias e "estórias", pp.152-166.Lisboa: Veja.

Casals Carro, M. J. (2005). Periodismo y sentido de la realidad. Teoría y análisis de la narrativa periodística. Madrid: Fragua.

Casero-Ripollés, A.; López Rabadán, P. (2012). La evolución del uso de las fuentes informativas en el periodismo español. Actas III Congreso Internacional "Comunicación y Riesgo". Tarragona, Universitat Rovira i Virgili. http://ae-ic.org/Tarragona/contents/comunicacions_cd/ok/311.pdf [Fecha de consulta: 08/05/2019].

Casero-Ripollés, A.; López Rabadán, P. (2013). La gestión de fuentes informativas como criterio de calidad profesional. En: Gómez Mompart, J.L; Gutiérrez, J.F.; Palau, D.(eds.), La calidad periodística: teorías, investigaciones y sugerencias profesionales, pp.73-91. Castelló de la Plana: Publicacions de la Univ. Jaume I; Valencia: Univ. de Valencia; Barcelona: Univ. Autónoma de Barcelona, Univ. Pompeu Fabra.

Chagas, L. (2019). Entre fontes e jornalistas: A seleção das vozes na construção das notícias na BandNews e na CBN. [Tesis Doctoral] Río de Janeiro (Brasil): Universidade Estadual do Rio de Janeiro.

Chaparro, M. C. (1994). Pragmática do jornalismo: buscas práticas para uma teoria da ação jornalística. São Paulo: Summus Editorial.

Deuze, M.; Witschge, T. (2016). O que o Jornalismo está se tornando. Parágrafo, 4 (2), 7-21. http://revistaseletronicas.fiamfaam.br/index.php/recicofi/article/ view/478/445 [Fecha de consulta: 03/04/2019].

Elías, C. (2003). Adaptación de la metodología de "observación participante" al estudio de los gabinetes de prensa como fuentes periodísticas. Empiria: Revista de Metodología de Ciencias Sociales, n. 6, 145-162. https://doi.org/10.5944/empiria.6.2003.938

Fontcuberta Balaguer, M. de (1993). La noticia. Pistas para percibir el mundo. Buenos Aires: Paidós. 
Franklin, B. (2011). Sources, credibility and the continuing crisis of UK journalism En: Franklin, B.; Carlson, M. (orgs.). Journalists, sources and credibility, pp. 90-107. Londres: Routledge. https:// doi.org/10.4324/9780203835708

Gans, H. J. (1980). Deciding what's news: a study of CBS Evening News, NBC Nightly News, Newsweek and Time. New York: Vintage.

García-Santamaría, J. V. (2010). Crisis del periodismo de fuentes. Las prácticas del periodismo en España en el accidente de Spanair. Revista Latina de Comunicación Social, n. 65, 516-537. https://doi.org/10.4185/RLCS65-2010-916-516-537

Gómez-Calderón, B.; Roses, S.; García-Borrego, M. (2017). Los nuevos perfiles profesionales del periodista desde la perspectiva académica española. Revista Mediterránea de Comunicación/Mediterranean Journal of Communication, 8 (1), 191-200. https://www.doi. org/10.14198/MEDCOM2017.8.1.14

Helmond, A. (2015). The platformatization of the web: Making web data platform ready. Social Media + Society, 1 (2), 1-11. https://doi. org/10.1177/2056305115603080

Herscovitz, H. G. (2007). Análise de Conteúdo em Jornalismo. En: Lago, C. e Benetti, M. (org.), Metodologia de Pesquisa em Jornalismo, pp. 123-142. Petrópolis: Editora Vozes.

Kischinhevsky, M. (2017). Radio y medios sociales - Mediaciones e interacciones radiofónicas digitales. BarceIona: Editorial UOC.

Kischinhevsky, M.; Chagas, L. (2017). Diversidade não é igual a pluralidade - Proposta de categorização das fontes no radiojornalismo. Galáxia. Revista do Programa de Pós-Graduação em Comunicação e Semiótica, 36, 111-124. http://dx.doi.org/10.1590/19822554233396

Krippendorff, K. (1990). Metodología de análisis de contenido. Teoría y práctica. Buenos Aires: Paidós comunicación.

Leal, B. S.; Jácome, P. (2013). Outros agentes na comunidade interpretativa do jornalismo. Rumores, 7 (14), 45-61. https://doi.org/10.11606/issn.1982-677X. rum.2013.69429

López, M. (1995). Cómo se fabrican las noticias. Fuentes, selección y planificación. Buenos Aires: Paidós.

López-García, X. (2002). Nuevos perfiles de los periodistas en la sociedad de la información. Ámbitos, n. 7-8, 7-18. https://idus.us.es/xmlui/bitstream/ handle/11441/67300/revista-comunicacion-ambitos-07-08_6-17.pdf? sequence $=1$ \&isAllowed $=y$ [Fecha de consulta: 08/02/2019].

López-García, X; Rodríguez-Vázquez, A. I.; Pereira-Fariña, X. (2017). Competencias tecnológicas y nuevos perfiles profesionales: desafíos del periodismo actual. Comunicar, XXV (53), 81-90. https://doi.org/10.3916/ C53-2017-08
Lopez, D. C. (2010). Radiojornalismo hipermidiático: tendências e perspectivas do jornalismo de rádio all news brasileiro em um contexto de convergência tecnológica. Covilhã: UBI/LabCom Books.

Manning, P. (2001). News and News Sources: A Critical Introduction. Londres: Sage.

Marques-Hayasaki, P.; Roca-Cuberes, C.; Casellas, C. S. (2016). New professional profiles and skills in the journalistic field: a scoping review and in-depth interviews with professionals in Spain. Brazilian Journalism Research, 12 (3), 14-33. https://doi.org/10.25200/BJR. v12n3.2016.904

Martín Bernal, O. (2012). Retratos robot del periodismo en el entorno digital. Los nuevos perfiles profesionales y laborales. En: Diezhandino, M. P. (coord.), El periodista en la encrucijada, pp.79-112. Barcelona: Ariel/ Fundación Telefónica.

Mayoral Sánchez, F. J. (2005). Fuentes de información y credibilidad periodística. Estudios sobre el Mensaje Periodístico, vol. 11, 93-102. https://revistas.ucm.es/index.php/ESMP/article/view/ESMP0505110093A/12446 [Fecha consulta: 15-08-2019].

Mayoral Sánchez, F. J.; Romero, J. M. (dirs.). (2009). El uso periodístico de las fuentes en radio y televisión. Madrid: Universidad Camilo José Cela.

Mellado, C.; Simon, J.; Barria, S.; Enríquez, J. (2007). Investigación de perfiles profesionales em periodismo y comunicación para uma actualización curricular permanente. Zer, 12 (23), 139-164. https://www.ehu. eus/ojs/index.php/Zer/article/view/3650/3282 [Fecha consulta: 04-05-2019].

Molotch, H.; Lester, M. (1999). A notícia como procedimento intencional: acerca do uso estratégico de acontecimentos de rotina, acidentes e escândalos. En: Traquina, N. (org.). Jornalismo: questões, teorias e "estórias", pp.34-51. Lisboa: Vega.

Moreira, S. V. (2016). O jornalista brasileiro contemporâneo. En: Amado, A.; Oller-Alonso, M.; Baumgratz, M. (org.), El periodismo por los periodistas, pp. 39-47. Montevideo: Konrad Adenauer Stifung Infociudadana.

Neveu, E. (2006). Sociologia do jornalismo. São Paulo: Loyola.

O'Neill, D.; O'Connor, C. (2008). The passive journalist: how sources dominate local news. Journalism Practice, 2 (3), 487-500, https://doi. org $/ 10.1080 / 17512780802281248$

Ortiz Sobrino, M. A. (2012). Radio y post-radio en España una cohabitación necesaria y posible. Área Abierta, 12 (2), 2-16 https://doi.org/10.5209/rev_ARAB.2012. n32.39637

Pablos Coello, J. M. de (2006). Fuentes mudas (en la web): periodismo transit propaganda. Estudios sobre el Mensaje Periodístico, v.12, 115-144. https:// revistas.ucm.es/index.php/ESMP/article/view/ ESMP0606110115A/12285 [Fecha de consulta: 08/07/2019]. 
Pereira, F. H. (2004). O jornalista sentado e a produção da notícia online no Correio Web. Questão, 10 (1), 95108. https://seer.ufrgs.br/index.php/EmQuestao/article/view/85 [Fecha consulta:07-03-2019].

Pérez-Curiel, C.; Gutiérrez Rubio, D.; Sánchez González, T.; Zurbano Berenguer, B. (2015). El uso de fuentes periodísticas en las secciones de Política, Economía y Cultura en el Periodismo de Proximidad Español. Estudios sobre el Mensaje Periodístico, 21 ( $\mathrm{n}^{\circ}$ especial), 101-117 https://doi.org/10.5209/rev_ESMP.2015. v21.50661

Reich, Z. (2011). Source Credibility as a Journalistic Work Tool. En: Franklin, B.; Carlson, M. (org.). Journalists, sources and credibility, pp.19-37. Londres: Routledge.

Rodríguez-Pallares, M. (2016). Propuesta conceptual de un modelo de gestión de contenidos y del conocimiento en la empresa radiofónica. Revista Española de Documentación Científica, 39 (2), 1-17. https://doi. org/10.3989/redc.2016.2.1271

Rodríguez-Rey, A.; Enguix A.; Rojas, J.L; García, M. (2015). La calidad de los medios y el uso de fuentes periodísticas en la prensa local de referencia en España. Estudios sobre el Mensaje Periodístico, 21 (no especial), 85-100, https://doi.org/10.5209/rev_ ESMP.2015.v21.50659

Salaverría, R. (2006). El nuevo perfil del periodista en el entorno digital. Actas de las XIII Jornadas de Jóvenes Investigadores en Comunicación - Nuevos retos de la comunicación: tecnología, empresa, sociedad (CDRom), pp.175-185. Zaragoza, 26-27 octubre 2006.

Salaverría, R.; García Avilés, J. A. (2008). La convergencia tecnológica en los medios de comunicación: retos para el periodismo. Trípodos, n. 23, 31-47. https:// www.raco.cat/index.php/tripodos/article/viewFile/118910/154114 [Fecha consulta: 09-03-2019].

Schlesinger, P. (1978). Putting 'reality together. Londres: Methuen.
Scolari, C. A.; Micó Sanz, J. L.; Navarro Guere, H.; Pardo Kuklinski, H. (2008). El periodista polivalente. Transformaciones en el perfil del periodista a partir de la digitalización de los medios audiovisuales catalanes. Zer, 13 (25), 37-60. https://www.ehu.eus/ojs/index. php/Zer/article/view/3572/3200 [Fecha consulta: 0802-2019].

Sigal, L. (1973). Reporters and Officials: The Organization and Politics of Newsmaking. Lexington: D. C. Heath.

Silva, G. ; Silva Da, M. P. ; Fernandes, M. L. (orgs.). (2014). Critérios de noticiabilidade. Problemas conceituais e aplicações. Florianópolis: Insular.

Srnicek, N. (2017). Platform Capitalism. Malden, MA: Polity Press.

Traquina, N. (2005). Teorias do jornalismo: a tribo jornalística - uma comunidade interpretativa transnacional. Vol. 2. Florianópolis: Insular.

Túñez López, J. M. ; Martínez Solana, Y.; Abejón Mendoza, P. (2010). Nuevos entornos, nuevas demandas, nuevos periodistas. Estudios sobre el Mensaje Periodístico, vol. 16, 79-94 https://revistas.ucm.es/index.php/ ESMP/article/view/ESMP1010110079A/11358 [Fecha consulta: 04-06-2019].

Van Hout, T. (2011). Sourcing Business News: A Case Study of Public Relations Uptake". En: Franklin, B.; Carlson, M. (org). Journalists, sources and credibility, pp.107-127.Londres: Routledge

White, D. (1999). O gatekeeper: uma análise de caso na selecção de notícias. En: Traquina, N. (org.). Jornalismo: questões, teorias e "estórias", pp. 142-151. Lisboa: Vega.

Zelizer, B. (2004). Taking Journalism Seriously. Thousand Oaks: Sage.

Zelizer, B. (2014). O que fazer com o jornalismo. Brazilian Journalism Research, 11 (2), 12-27. https://doi. org/10.25200/BJR.v10n2.2014.737 